\title{
Evaluation of Diagnosing Tuberculosis in Primary Care Medicine in Mureș County, Between 2006 and 2008
}

\author{
Ács Valeria ${ }^{1}$, Finta Hajnal ${ }^{2}$, lanosi Edith Simona ${ }^{3}$, Sabău Monica ${ }^{4}$ \\ 1 Doctoral School, University of Medicine and Pharmacy, Tîrgu Mureș, Romania \\ 2 Department of Hygiene, University of Medicine and Pharmacy, Tîrgu Mureș, Romania \\ 3 Department of Pulmonology, University of Medicine and Pharmacy, Tîrgu Mureș, Romania \\ ${ }^{4}$ Department of Epidemiology, University of Medicine and Pharmacy, Tîrgu Mureș, Romania
}

\begin{abstract}
Aim: Evaluation of the contribution of general practitioners to the early diagnosis of tuberculosis in the studied period. Analysis of cases not diagnosed as active TB, from those suspected by the general practitioner and the real cases with respiratory lesions.

Material and methods: We conducted an observational epidemiologic study aiming at evaluating the diagnosis of pulmonary TB at the level of primary care medicine.

Results: The difference between conformed TB patients that have been referred with the suspicion of TB and those without suspicion is significant $(p<0.0001)$, and the risk of disease estimated by OR was 21.54. More than half of the patients (139), had positive microscopic examination and culturing, representing $62.61 \%$. In 10.36\% microscopic examination was positive and culturing was negative (13 patients). Negative microscopic examination and positive culturing were detected in $5.86 \%$ of the patients. The majority of suspected/confirmed new patients were living in urban environments. The urban/rural ratio was 1.27. The reasons why the general practitioner suspected tuberculosis, in the order of frequency, were the following: cough/dry cough, sweating/nocturnal sweating, fever/persisting fever. Among the TB types, we noted the large percentage of patients with infiltrating, nodular tuberculosis confined to the volume of one pulmonary segment (30.78\%), and $19.87 \%$ of the cases were multicavity tuberculosis; also, we noted the presence of caseous tuberculosis with moderate volumes of infiltrates, confined to a pulmonary lobe (18.27\%).
\end{abstract}

Conclusion: Early diagnosis of tuberculosis in the primary healthcare network is a continuous challenge for the general practitioner.

Keywords: tuberculosis, general practitioner, suspect of tuberculosis

Received: 3 January 2013

\section{Introduction}

Although the number of tuberculosis cases is dropping continually since 2002, Romania is one of the most affected countries by the Koch bacillus infection, which represents a major public health issue with important social and economic impact. The National Strategy for Control of Tuberculosis 2007-2011 has been developed based on the directions set forth by the WHO Global Plan for Stopping Tuberculosis 2006-2015. Achievement of the proposed goals requires active involvement of all responsible factors from the healthcare network, especially general practitioners, who act as "gatekeepers" and have a key role in the early diagnosis of the disease, and active prophylaxis and monitoring of post-hospital therapy. Early diagnosis of tuberculosis in the primary healthcare network is a continuous challenge for the general practitioner.

\section{Objectives}

1. Analysis of the ratio of cases diagnosed with active tuberculosis from the total number of the cases with TB suspicion (based on eligibility criteria) referred by the general practitioners.

2. Analysis of cases referred by general practitioners with $\mathrm{TB}$ suspicion who have not been diagnosed with active TB.

3. Analysis of suspicion criteria for TB, that are used in primary care medicine.

4. Elaboration of recommendations for optimizing prevention measures.

\section{Material and methods}

We conducted an observational epidemiologic study aiming at evaluating the diagnosis of pulmonary $\mathrm{TB}$ at the level of primary care medicine in the Mures area between 2006 and 2008.

The patient group consisted of 16,076 patients referred by the general practitioners to the Pulmonology Policlinic (DPF) from Tîrgu Mureș for consultation. The group has been divided as follows: referred with the suspicion of pulmonary $\mathrm{TB}=516$ patients and referred without the suspicion of pulmonary $\mathrm{TB}=15,560$ patients.

The data has been obtained from:

1. The referring notes issued by the general practitioners brought in by the patients who came to the Pulmonology Policlinic from Tîrgu Mureș for consultation; 
2. Consultation registries from the TBC Policlinic from Tîrgu Mureș;

3. Special tuberculosis registries from the policlinic;

4. Reporting sheets for the tuberculosis cases;

5. Consultation sheets from the general practitioner's offices.

Inclusion criteria: new patients with pulmonary $\mathrm{TB}$ (new cases and recurrences) diagnosed at the DPF from Tîrgu Mureș between 2006 and 2008, who presented at the policlinic with a referral from the general practitioner with or without the diagnosis of "Suspect of tuberculosis".

Exclusion criteria: the following patients have been excluded from the study:

1. New patients with pulmonary TB (new cases and recurrences) diagnosed at other regional centers from Mures county

2. Patients who presented at the (DPF) from Tîrgu Mureș for consultation without referral note from the general practitioner.

3. Patients with extrapulmonary tuberculosis

In case of the patients with the diagnosis of "Suspect of tuberculosis" and confirmed by the specialist, the distribution has been performed based on the following: address, sex, age, occupation category, actual methods used for diagnosis, reasons for suspicion/referral, clinical form, and hospital stay. New patients with pulmonary TB (new cases and recurrences) from the suspected/confirmed category have been studied as a group and separated into new cases and recurrent cases.

In case of the patients with the diagnosis of "Suspect of tuberculosis" and not confirmed by the specialist, we studied the same parameters, while including the real diagnoses of the patients.

\section{Results}

During the studied timeframe the specialists at the Pulmonology Policlinic from Tîrgu Mureș performed 23,996 consultations. Out of the examined patients, 16,076 presented at the policlinic with referral notes issued by the general practitioners (66.99\%).

The patient group consisted of 516 patients referred between 2006 and 2008 by the general practitioners to the Pulmonology Policlinic from Tîrgu Mureș for consultation and diagnosis, with the diagnosis of "Suspect of tuberculosis".

Table I. Patients referred by general practitioners to pulmonology consultations between 2006 and 2008

\begin{tabular}{lccc}
\hline & $\begin{array}{c}\text { No. of patients } \\
\text { with TB }\end{array}$ & $\begin{array}{c}\text { No. of patients } \\
\text { without TB }\end{array}$ & Total \\
\hline $\begin{array}{l}\text { No. of patients referred by the } \\
\text { GP with "Suspect of TB" }\end{array}$ & 222 & 294 & 516 \\
$\begin{array}{l}\text { No. of patients referred by the } \\
\text { GP with a diagnosis other than } \\
\text { "Suspect of TB" }\end{array}$ & 527 & 15,033 & 15,560 \\
\begin{tabular}{l} 
Total \\
\hline
\end{tabular} & 749 & 15,327 & 16,076 \\
\hline
\end{tabular}

Out of the 516 patient presenting at the DPF Tîrgu Mureș with suspicion of tuberculosis, the diagnosis has been confirmed by the specialist in case of 222 patients (43.02\%); in case of 294 cases $(56.98 \%)$ the suspected diagnosis of tuberculosis has not been confirmed, and the real diagnosis was a different respiratory condition.

The difference between conformed TB patients that have been referred with the suspicion of $\mathrm{TB}$ and those without suspicion is statistically significant $(\mathrm{p}<0.0001)$, and the risk of disease estimated by OR is 21.54 (Table I).

The analysis of the group of new TB patients (new case or recurrence), suspected/confirmed, based on categories of cases and therapeutic history showed that 184 patients were new cases $(82.88 \%)$, i.e. without tuberculosis in the patient history, and 38 patients were recurrences (17.12\%).

Based on living environments, 122 patients were living in urban areas, representing $54.95 \%$ of the cases. 100 patients $(45.05 \%)$ were based in rural areas. The ratio between urban/rural was 1.22 .

Analysis according to sex revealed that males (146 patients) represented $65.77 \%$ of the suspected/confirmed cases, and women $37.23 \% .59 .21 \%$ of the female patients were based in urban areas. The same tendency was noted in case of males, where $52.74 \%$ were based in cities.

Age analysis showed that the most frequent age category was between 25 and 54 years, representing $67.57 \%$ of the total population. Most of the cases were based in urban areas.

In case of male patients the most frequent age category was between 45 and 54 years, representing $25.35 \%$ of the total number of males, and a majority of these patients were living in rural areas (Figure 1).

Analysis of occupation showed that the ratio of patients without a job was the highest (37.39\%). Over 20\% of the patients were retired. A low percentage was taken up by patients with higher education $(3.15 \%)$. The ratio of patients working in the healthcare system was minute $(1.80 \%)(\mathrm{Ta}-$ ble II).

Regarding the result of the bacteriology examination, more than half of the patients (139) had a positive mi-

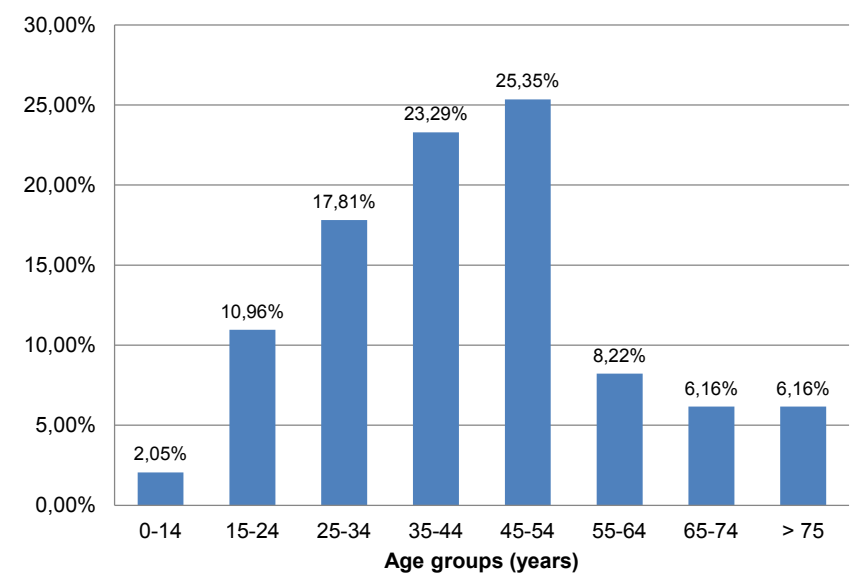

Fig. 1. Distribution of new TB patients (new cases or recurrences), suspected/confirmed according to age - males 
Table II. Number of new TB patients (new cases or recurrences), suspected/confirmed according to the result of the bacteriology examination

\begin{tabular}{lccc}
\hline & $\begin{array}{c}\text { Positive } \\
\text { microscopy }\end{array}$ & $\begin{array}{c}\text { Negative } \\
\text { microscopy }\end{array}$ & Chi square test \\
\hline Positive culture & 139 & 13 & $\mathrm{p}<.005$ \\
Negative culture & 23 & 47 & $\mathrm{p}<0.0001$ \\
\hline
\end{tabular}

croscopic and culture results, representing 62.61\%. In $10.36 \%$ microscopic examination was positive and culturing was negative (13 patients). Negative microscopic examination and positive culturing were detected in $5.86 \%$ of the patients (Table II).

Bacteriology testing was negative in $21.17 \%$ of the cases.

In case of the patients with the diagnosis of "Suspect of tuberculosis" on the referral note, the general practitioners gave the following reasons for referral, in the order of frequency: cough/dry cough (87 cases), asthenia/fatigability (46 cases), fever/persistent fever (39 patients), weight loss (37 patients), sweating/ nocturnal sweating (29), dyspnea (25), subfebrility/persistent subfebrility (23), repeated pneumonias (14), treatment resistant bronchitis (14), hemoptysis/repeated minor hemoptysis (12), cachexia (11), treatment resistant bronchopneumonia (4 patients). (Table III).

The suspected diagnosis has been supported with symptoms/syndromes in $82.43 \%$ of the cases; there was one symptom/syndrome in $28.38 \%$ of the cases, two symptoms/syndromes in the same percent of the cases and three symptoms/syndromes in $21.62 \%$ of the cases. In a small number of patients (8) the suspected diagnosis was upheld by four symptoms/syndromes. In 39 cases the patients have been referred with the suspicion of pulmonary TB, but without motivation of the suspicion (17.57\%).

In case of new, suspected/confirmed TB patients (new cases or recurrences) the most frequent form of TB confirmed by the specialist was infiltrating, nodular tuberculosis confined to the volume of one pulmonary segment (56 cases). In a significant number of patients multicavity tuberculosis has been identified (55). Caseous extensive forms of tuberculosis (pneumonias, bronchopneumonias, ulcerated infiltrates, with extension to two pulmonary
Table III. Reasons for referral formulated by the GPs in case of new TB patients (new cases or recurrences) suspected/confirmed

\begin{tabular}{lccc}
\hline $\begin{array}{l}\text { Reasons for suspecting } \\
\text { pulmonary TB }\end{array}$ & $\begin{array}{c}\text { No. of } \\
\text { patients }\end{array}$ & $\begin{array}{c}\text { Frequency } \\
(\%)\end{array}$ & $\begin{array}{c}\text { Confidence } \\
\text { interval (95\%) }\end{array}$ \\
\hline Cough/dry cough & 87 & 25.51 & $21.17-30.39 \%$ \\
Asthenia/fatigability & 46 & 13.49 & $10.27-17.53 \%$ \\
Fever/persistent fever & 39 & 11.44 & $8.48-15.26 \%$ \\
Weight loss & 37 & 10.85 & $7.97-14.6 \%$ \\
Sweating/ nocturnal sweating & 29 & 8.50 & $5.98-11.94 \%$ \\
Dyspnea & 25 & 7.33 & $5.01-10.6 \%$ \\
Subfebrility/persistent subfebrility & 23 & 6.74 & $4.53-9.91 \%$ \\
Repeated pneumonias & 14 & 4.11 & $2.46-6.78 \%$ \\
Treatment resistant bronchitis & 14 & 4.11 & $2.46-6.78 \%$ \\
Hemoptysis/repeated minor & 12 & 3.52 & $2.03-6.05 \%$ \\
hemoptysis & & & \\
Cachexia & 11 & 3.23 & $1.81-5.69 \%$ \\
Treatment resistant & 4 & 1.17 & $0.46-2.97 \%$ \\
bronchopneumonia & & & \\
\hline
\end{tabular}

lobes) (17.57\%), and single cavity tuberculosis, described as a cavity circumscribed by its own wall, with a diameter of at least $2 \mathrm{~cm},(16.67 \%)$ occurred in approximately similar number of cases (Table IV).

Out of the 222 patients, 19 have been isolated and treated at home (8.56\%). $91.45 \%$ of the newly registered patients have been hospitalized for paraclinical examinations and initiation of chemotherapy.

Most of the patients have been hospitalized between 31 and 90 days, representing $35.14 \%$ of the cases. Patients hospitalized more than 90 days represented a relatively small percent $(1.80 \%)$. Hospital stay for these patients summed up a total of 6066 days, with a mean of 27.32 days.

After analysis of cases where general practitioners suspected tuberculosis that later has been invalidated by pulmonology specialists, we found the following:

Analysis of cases based on residential area showed that the number of patients based in rural areas (165 patients) was higher than the number of patients from urban environments (129).

The male/female gender ratio was 1.12 . The proportion of male patients was higher in case of rural based patients $(54.84 \%)$. In case of women, most of them were based in rural areas $(57.55 \%)$, and a lesser proportion in urban areas $(42.45 \%)$.

Table IV. TB forms in the group of patients with new, suspected/confirmed TB (new cases or recurrences)

\begin{tabular}{|c|c|c|c|}
\hline TB form & $\begin{array}{l}\text { No. of } \\
\text { patients }\end{array}$ & $\begin{array}{l}\text { Frequency } \\
\quad(\%)\end{array}$ & $\begin{array}{l}\text { Confidence interval } \\
(95 \%)\end{array}$ \\
\hline Infiltrating, nodular tuberculosis confined to the volume of one pulmonary segment & 56 & 25.23 & $19.97-31.57 \%$ \\
\hline $\begin{array}{l}\text { Caseous extensive tuberculosis (pneumonias, bronchopneumonias, ulcerated infiltrates, with } \\
\text { extension to two pulmonary lobes) }\end{array}$ & 39 & 17.57 & $13.13-23.12 \%$ \\
\hline Single cavity tuberculosis (a cavity circumscribed by its own wall, with a diameter of at least $2 \mathrm{~cm}$ ) & 37 & 16.67 & $12.34-22.13 \%$ \\
\hline Caseous tuberculosis with medium sized infiltrates, extending to a pulmonary lobe & 33 & 14.86 & $10.78-20.14 \%$ \\
\hline Tuberculoma & 1 & 0.45 & $0.08-2.51 \%$ \\
\hline Tuberculosis of the pulmonary parenchyma, not otherwise specified & 1 & 0.45 & $0.08-2.51 \%$ \\
\hline Total & 222 & 100 & \\
\hline
\end{tabular}




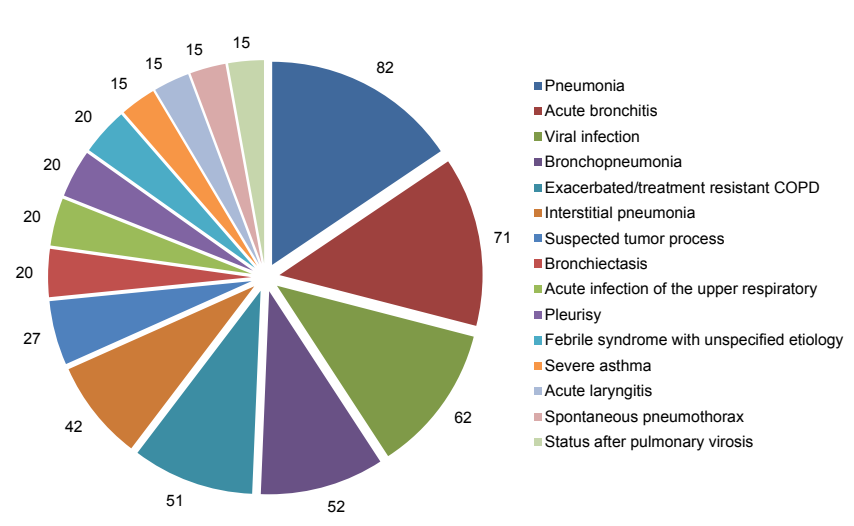

Fig. 2. Distribution of new TB patients (new cases or recurrences), not suspected by the GPs, according to referral diagnosis

Analyzing age groups, both in case of women (20.86\%) and men $(17.42 \%)$, the most frequent suspected/unconfirmed TB age group was between 45 and 54 years.

The most frequent reasons that determined the general practitioners to raise the diagnosis of suspect of tuberculosis were cough and dry cough. A significant number of patients have been suspected of tuberculosis as they had subfebrility and persistent subfebrility (46), hemoptysis or minor repeated hemoptysis (31) 69 patients were suspected of tuberculosis because they were TB contacts.

In order to confirm or invalidate the diagnosis of ,,Suspect of pulmonary tuberculosis", the specialists requested chest X-ray in almost half of the patients (43.54\%), and over $25 \%$ of the patients have been examined by microradiography (MRF). The two examinations have been combined in $6.80-7.14 \%$ of the cases.

In $8.50 \%$ of the cases the specialist considered that paraclinical examination was not necessary to invalidate the suspicion diagnosis of the general practitioner.

In the studied period we found that in 527 of the new cases (new cases and recurrences) diagnosed at the DPF Tîrgu Mureș, the general practitioners referred the patients to the specialist with a diagnosis of a respiratory condition that subsequently turned out to be tuberculosis (70.36\%).

The most frequent pulmonary condition referred by the general practitioners to the specialists was pneumonia $(15.56 \%)$, followed by prolonged acute bronchitis $(13.47 \%)$ and respiratory viral infections (11.76\%). Tumors were suspected in case of 27 patients, representing $5.12 \%$ of the cases (Figure 2).

The most frequent symptom, which was used as a basis for formulation of the preliminary diagnosis was cough/ dry cough $(36.49 \%)$. Fever, chest pain, asthenia/fatigability and subfebrility occurred in an approximately equal proportion.

Among the TB forms we noted the large proportion of patients with infiltrating, nodular tuberculosis confined to the volume of one pulmonary segment $(30.78 \%)$. Multicavity tuberculosis $(19.87 \%$ ) and caseous tuberculosis with medium sized infiltrates, extending to a pulmonary lobe
$(18.27 \%)$ were also diagnosed in a relatively high percent of the cases.

\section{Discussions}

Although the TB burden is decreasing worldwide, the progress achieved in controlling tuberculosis, and especially early diagnosis is not as expected $[1,2,3]$. In most of the countries suspicion diagnosis and follow-up of the antituberculosis treatment is the responsibility of primary healthcare providers.

A major issue of controlling and fighting tuberculosis worldwide is late detection of the disease. Reports emphasize that in many countries, patients with persisting respiratory symptoms, including those with TB symptoms, are not suspected of tuberculosis at the level of primary care, and screening of eligible patients is often neglected [2].

In our study, in case of the patients with the diagnosis of "Suspect of tuberculosis", general practitioners had a correct suspicion for the presence of tuberculosis in $43.02 \%$. In more than half of the cases the patient suspected of tuberculosis had a different respiratory condition.

In case of patients with new, suspected/confirmed TB (new cases and recurrences) a larger proportion consisted of new TB cases, so without tuberculosis in the patient history, as opposed to recurrent cases. Comparing the incidence of new tuberculosis cases with new and recurrent tuberculosis cases that were reported during the studied period, we noted that general practitioners diagnosed more correctly the presence of tuberculosis in case of patients with a history of TB.

Male patients dominated both in urban and rural environments, regarding new cases and recurrences as well. The ratio was 1.92, corresponding to data recorded in Romania (sex ratio in the studied period was 2.3) and the EU Region of the WHO (sex ratio 2.0) [4,5]. Regarding new $\mathrm{TB}$ cases in the male population, the age groups between 35 and 44, and 45 and 54 years had the same proportion (23.08\%); this also was in accordance with data recorded nationally and literature data [6].

Almost half of the patients were unemployed (37.39\%). A significant percent was represented by the retired patients (20.72). Poverty is an important risk factor for tuberculosis. A study performed to establish the incidence of tuberculosis occurring in vulnerable populations demonstrated that in Romania, between 2006 and 2008, more than 25\% of the new cases were unemployed individuals [7].

The reason for suspecting tuberculosis in a large number of patients was cough, accompanied by signs of bacillus impregnation: asthenia, fatigability, weight loss, sweating, and nocturnal sweating. In case of recurring patients, the reasons for suspecting TB were cough, sweating and persistent fever.

The most frequently diagnosed radiologic form of TB was infiltrating, nodular tuberculosis confined to the volume of one pulmonary segment (25.23\%). In a significant number of patients, cavitary tuberculosis has been identified $(24.77 \%)$. 
Mean duration of hospital stay was 27.32 days, which is more than the value achieved in Pulmonology Departments in Romania (19.6\%) [8]. The duration of hospital stay depends on the conversion of direct sputum testing and conversion of cultures [9].

The obtained data are comparable to the results of the 2007 study. It has been established that in countries where the DOTS program was working well (e.g. Great Britain or Italy), mean duration of hospital stay for TB patients was between 14 and 38 days, as opposed to Russia (86 days), where correct implementation of the DOTS strategy has not been successful [10].

In case of most of the patients with suspected TB by the general practitioner, and subsequent invalidation of this diagnosis by the specialist, the reason for suspicion was cough. Cough, subfebrility/persisting subfebrility, and fever/persistent fever also represented reasons for suspecting TB. Literature data emphasized that clinical symptoms and signs of pulmonary tuberculosis are neither specific to tuberculosis nor mandatorily present in all patients, and a large number of patients are oligosymptomatic $[11,12]$.

In $15.58 \%$ of the cases the status of "TB contact" was the reason why general practitioners suspected tuberculosis. Some studied demonstrate that over $60 \%$ of new patients are $\mathrm{TB}$ contacts [13].

\section{New TB patients, without suspicion of tuberculosis}

Out of the 527 patients diagnosed at the DPF Tîrgu Mures, with pulmonary tuberculosis, the patients where general practitioners did not raise the suspicion of tuberculosis represent a proportion of $70.36 \%$ of the new TB cases (new cases and recurrences). These patients have been referred to the policlinic for a different respiratory condition. According to literature data, in England tuberculosis is the most frequent incorrectly diagnosed pulmonary disease [14].

Pulmonary tuberculosis can be underlying another pulmonary condition or a systemic disease $[15,16]$.

Among the patients with no suspicion of $\mathrm{TB}$, a large proportion was diagnosed with infiltrating, nodular tuberculosis confined to the volume of one pulmonary segment. In a large number of patients (although under 20\%) multi-cavitary tuberculosis, and extensive caseous tuberculosis (pneumonias, bronchopneumonias, ulcerated infiltrates, with extension to two pulmonary lobes) have been diagnosed. According to literature data, 55-60\% of infiltrating tuberculosis cases have a prolonged, asymptomatic onset, especially in case of confined lesions, and the disease is frequently discovered by accident, by an X-ray examination [17].

\section{Conclusions}

1. Out of the 516 patients referred by the general practitioners to the Pulmonology Policlinic from Tîrgu Mureș with "Suspicion of tuberculosis", the specialists confirmed the diagnosis in $43 \%$ of the cases. General practitioners diagnosed more accurately the presence of tuberculosis in recurring patients, who had TB in their medical history.

2. Suspected/confirmed new patients were mostly based in urban areas, demonstrating the carefulness of general practitioners in this environment when meeting a case with suspicion of tuberculosis. They preferred overdiagnosis and referral of the patients to the specialist to clarify the diagnosis.

3 . In the group of patients suspected of $\mathrm{TB}$ and subsequently confirmed, the dominant age group was 24 35 years for women, and 45-54 years for men. This confirms that the risk of tuberculosis is higher in the young and middle aged population.

4. A large percent of the patients were unemployed. The high rate of suspected/confirmed case among unemployed individuals reveals that the general practitioner consider poverty as a risk factor for TB.

5. A large number of patients had positive microscopic examination results. These patients represent an important source of infection and disease propagation. Early detection of bacilliferous cases by the general practitioners has to be positively appreciated. Bacteriology testing (microscopic and culture) was negative in $21.17 \%$ of the cases. These represent the bacteriologically unconfirmed cases where the specialist considered that chemotherapy was required, demonstrating that general practitioners did not make a mistake when suspecting TB in these patients.

6. In case of new, suspected/confirmed TB patients the most frequent radiological form was infiltrating, nodular tuberculosis confined to the volume of one pulmonary segment, while in recurring cases multi-cavitary tuberculosis, and extensive caseous tuberculosis (pneumonias, bronchopneumonias, ulcerated infiltrates) dominated. Considering that these forms of the disease are highly contagious, early detection by the general practitioners is highly appreciated. These represent real walking sources of infection.

7. The reasons for suspecting tuberculosis in suspected/ unconfirmed patients were not substantially different from clinical manifestations of pulmonary tuberculosis, but it is well known that clinical symptoms and signs of pulmonary tuberculosis are neither specific to tuberculosis nor mandatorily present in all patients, and a large number of patients are oligosymptomatic. These are guidelines for establishment of the tuberculosis diagnosis.

8. At a first glance this is a negative result as far the efficiency of general practitioners is concerned in diagnosing pulmonary tuberculosis, but it should be appreciated that general practitioners requested correctly the specialist consultations in order to clarify the diagnosis.

9. The most frequent condition prompting general practitioners to request specialist consultation was pneumonia, followed by prolonged acute bronchitis, respiratory viral infections, bronchopneumonia, exacerbated/treatment resistant COPD. Pulmonary tuberculosis can be underlying another pulmonary condition or a systemic 
disease. Tuberculosis and chronic bronchitis, tuberculosis and non-specific inflammations of the upper airways or the whole bronchial tree are associations that may hide tuberculosis, and hinder early diagnosis of the disease by the general practitioner.

\section{References}

1. Department of Health and Human Service, Center for Disease Control and Prevention. Controlling Tuberculosis in the US, www.cdc.gov/tb/

2. Me'emary F, Ottmani SE, Pio A, et al. Results of the feasibility test of the Practical Approach to Lung Health in Siria. Eastern mediterranean Health Journal, 2009;15(3):504-15.

3. Ribeiro SA, Matsui TN. Admission for tuberculosis to a university hospital. J. Pneumologia. 2003;29(1):9-14.

4. European Center for Disease Prevention and Control/WHO Regional Office for Europe, Tuberculosis surveillance in Europe 2007, Stockholm, European Center for Disease Prevention and Control, 2009

5. European Center for Disease Prevention and Control/WHO Regional Office for Europe, Tuberculosis surveillance in Europe 2008, Stockholm, European Center for Disease Prevențion and Control

6. Yamagushi F, Toyota M. Research and Control of relapse tuberculosis cases. Kekkaku. 2009;84(12):767-8.

7. Didilescu NC, Marica C, Chițan Domnica. Aspecte epidemiologice ale tuberculozei survenite la categoriile vulnerabile. Revista Medicală Română. 2010;LVII(1):25-30.
8. Cristea C. Evoluția tuberculozei în anii 1999-2011, Ministerul Sănătății, Institutul Național de Sănătate Publică, Centrul Național de Statistică și Informatică în Sănătate Publică, 2012

9. Marica C, Tănăsescu Mihaela, Didilescu C, Chioțan Domnica, Popescu Hagen Mara. Tuberculoza multidrog rezistentă în România în ultimii ani (2004-2007) - Un fenomen social de maximă importanță. Revista Medicală Română. 2009;LVI:4.

10. Marx FM, Atum RA, Jakubowiak W, McKee M, et al. Reform of tuberculosis control and DOTS within Russian public health systems: an ecological study. Europian Journal of Public Health. 2007;17(1):98-103.

11. Jimborean Gabriela, lanosi Edith Simona. Aparatul respirator, semiologie și clinică medicală, Tehnica îngrijirii pacienților cu boli respiratorii. Biblioteca UMF Târgu-Mureș, 2007

12. Jimborean Gabriela, Simon K, Platon A. Aspecte ale tuberculozei pleurale în jud. Mureș (1994-1999). Rev de Medicină și Farmacie, UMF Tg. Mureș. 2000;46(1-2):104-107.

13. Soomro JA, Qazi HA. Factors Associated with Relapsed Tuberculosis in Males and Females: A Comparative Study. Tanaffos. 2009;8(3):22-27.

14. Davies P. Tuberculosis: current problems for primary care, a danger of complacency? Prim Care Resp J. 2003;12(4):105-106.

15. Baras ES. Reasons for the late diagnosis of pulmonary tuberculosis in the outpatient polyclinic network. Probl Tuberk, 1989;(9):14-6.

16. Păunescu-Podeanu A. Bazele clinice pentru practica medicală, Vol. III. Editura Medicală, București, 1984, 932-943.

17. Păun R. Bolile aparatului respirator, Vol. I, Editura Medicală, București, 1983, 408-409. 